\title{
Unmanned Aerial Vehicle Robot untuk Pemadam Api dengan Rancangan Alat Pemadam yang Efisien
}

\author{
Ardiansyah Al Farouq ${ }^{1 *}$, Moch. Iskandar Riansyah ${ }^{2}$, and Ahmad Habibi ${ }^{1}$ \\ ${ }^{1}$ Teknik Komputer, Fakultas Teknik Elektro, Institut Teknologi Telkom Surabaya, Indonesia \\ ${ }^{2}$ Teknik Elektro, Fakultas Teknik Elektro, Institut Teknologi Telkom Surabaya, Indonesia \\ "Corresponding author, e-mail: alfarouq01@gmail.com
}

\begin{abstract}
Abstrak - Pada saat petugas pemadam api melakukan pemadaman api terdapat beberapa titik tertentu yang sulit dilalui, sedangkan kecepatan dalam pemadaman adalah yang penting. Oleh sebab itu adanya UAV (Unmanned Aerial Vehicle) yang dapat dengan mudah menjangkau daerah tersebut sangatlah penting untuk membantu para pemadam. Kemudian alat pemadam yang digunakan untuk memadamkan juga harus dirancang khusus karena kemampuan angkut UAV (Unmanned Aerial Vehicle) robot terbatas. Desain UAV (Unmanned Aerial Vehicle) robot terbang yang digunakan adalah berbentuk multicopter robot. Multicopter yang didesain memiliki 6 baling-baling. Kemudan alat pemadam yang dirancang juga dirancang khusus agar dapat memadamkan api dengan efisien dengan multicopter yang telah didesain. Alat pemadam yang dirancang berupa payung terbalik yang bagian kaiin payung menggunakan kain pemadam atau kain tahan api yang biasa digunakan untuk memadamkan api. Dengan desain sistem tersebut maka UAV robot sangat efisien digunakan untuk memadamkan api dalam bentuk multicopter. Alat pemadam yang dirancang telah berhasil 100\% memadamkan api dengan rata-rata waktu 5 detik, sedangkan bila menggunakan air maka api padam dalam waktu rata-rata 37.5 detik.
\end{abstract}

Kata Kunci : UAV, Robot, Pemadam kebakaran, Multicopter, Alat pemadam.

\begin{abstract}
When firefighters extinguish a fire there are certain points that are difficult to pass, while the speed of extinguishing the fire is important. Therefore, the existence of a UAV (Unmanned Aerial Vehicle) that can easily reach the area is very important to help the firefighters. Then the extinguisher used to extinguish must also be specially designed because the ability to carry the robot's UAV (Unmanned Aerial Vehicle) is limited. The flying robot UAV (Unmanned Aerial Vehicle) design used is a multicopter robot. Multicopter which is designed to have 6 propellers. Specially designed extinguisher is also designed to be able to extinguish the fire efficiently with the designed multicopter. The extinguisher is designed in the form of an inverted umbrella with the fabric of the umbrella using a fire extinguisher or a fire-resistant cloth. With this system design, the robot UAV is very efficient to use to extinguish fire in the form of a multicopter. The extinguisher designed has succeeded 100\% in extinguishing the fire with an average time of 5 seconds, while when using water the fire is extinguished in an average time of 37.5 seconds.
\end{abstract}

Keywords : UAV, Robot, Fire fighting,Mmulticopter, Extinguisher.

\section{Pendahuluan}

Indonesia adalah negara berkembang dan sudah memiliki banyak kota yang padat penduduk. Kebakaran sudah menjadi ancaman potensial yang menyebabkan hilangnya nyawa, kerusakan properti, dan cacat permanen bagi korban yang terkena dampak. Penanganan pemadaman kebakaran di Indonesia masih kurang memanfaatkan kemajuan teknologi yang ada. Pada proses pemadaman sering kali terdapat beberapa titik yang susah di lalui. Hal ini menyebabkan proses pemadaman berakhir lama. Maka perlu adanya sentuhan teknologi untuk membantu para pemadam agar dapat meringankan permasalahan tersebut. Contohnya menggunakan teknologi robot. Robot adalah perangkat otomatis yang melakukan fungsi yang biasanya dikaitkan dengan manusia atau mesin yang bertugas melakukan serangkaian tindakan berulang atau fleksibel. Robot yang didesain juga harus memiliki strukut nirkabel yang baik [1]. Sejumlah penelitian telah menunjukkan bahwa robot dapat bermanfaat dalam kedokteran, rehabilitasi [2-6], operasi penyelamatan [7, 8] dan industri [9]. Selama bertahun-tahun, robotika telah diperkenalkan di 
berbagai industri. Robot industri adalah manipulator multi-fungsi yang dirancang dari perangkat-perangkat khusus yang terprogram untuk melakukan berbagai tugas[10]. Sejalan dengan revolusi Industri 4.0, dimana dorongan untuk membangun sistem yang dapat dikendalikan, berkomunikasi dan mengintegrasikan robot yang berbeda terlepas dari jenis dan spesifikasinya. Jenis-jenis robot yang dimaksud disini seperti Unmanned Aerial Vehicle (UAV), humanoid robot, dan lain-lain.

Studi tentang Unmanned Aerial Vehicle (UAV) atau dalam bahasa Indonesia disebut pesawat tanpa awak ini dilakukan untuk meminimalkan cedera dan kematian petugas kebakaran serta meningkatkan keselamatan, produktivitas, kualitas, dan efisiensi tugas para pemadam kebakaran[aall]. UAV robot memiliki beberapa jenis seperti robot Tele, robot Telepresence, robot Mobile, dan robot autonomous. Robot telepresence mirip dengan robot tele dengan perbedaan utama dalam memberikan umpan balik dari video, suara, dan data lainnya. Oleh karena itu, robot tele-presence banyak digunakan di banyak bidang yang membutuhkan kemampuan pemantauan, seperti dalam pengmbangan anak dan pendidikan, dan untuk meningkatkan kegiatan sosial dan sehari-hari orang dewasa yang lebih tua $[11,12]$. Robot mobile dirancang untuk menavigasi dan melaksanakan tugas dengan intervensi manusia [13, 14]. Sementara itu, robot autonomous dapat melakukan tugas secara mandiri sesuai lingkungannya[15,16].

Penelitian ini bertujuan membangun suatu robot UAV yang berfungsi untuk pemadam kebakaran. Fungsi utama robot UAV yang dikembangkan untuk mencari dan memadamkan api. Ada beberapa jenis kendaraan yang digunakan untuk pemadam kebakaran di rumah, gedung dan kebakaran hutan [17]. Robot UAV yang didesain untuk dapat bekerja sendiri atau dikendalikan dari jarak jauh. Dengan menggunakan robot UAV seperti itu, maka identifikasi kebakaran dan kegiatan penyelamatan dapat dilakukan dengan lebih aman dan mengurangi resiko pada petugas pemadam kebakaran pada kondisi yang berbahaya. Dengan kata lain, robot UAV dapat mengurangi resiko pemadam kebakaran untuk masuk ke situasi berbahaya. Selain itu, robot UAV memiliki ukuran yang relatif kecil disbanding ukuran manusia dan kendali jarak jauh memungkinkan robot UAV untuk digunakan ketika kebakaran terjadi di ruang sempit dan kecil dengan lingkungan berbahaya seperti terowongan atau pembangkit listrik tenaga nuklir[17-19].

Matrice 200 dan DSLRPros Matrice 210 adalah dua robot UAV pemadam kebakaran yang tersedia saat ini yang telah digunakan secara luas di industri. Robot UAV tersebut dibangun untuk bertahan, dirancang untuk beradaptasi. Robot UAV tersebut adalah alat udara pemungkas, dibangun untuk inspeksi industry dan operasi keselamatan publik. Robot UAV tersebut dilengkapi kamera dan mampu memanfaatkan gimbal tunggal ke bawah, gimbal danda untuk inspeksi visual dan monitor area yang sulit dijangkau. Selain terdapat layar ultra terang yang terlihat jelas di bawah sinar matahari. Monitor telah dirancang dari bawah ke atas untuk bekerja secara lancer dengan aplikasi yang sudah dikembangkan[15].

Dalam penelitian ini, robot UAV pemadam kebakaran yang dibuat adalah memiliki ukuran yang tidak besar (dimensi $<90 \mathrm{~cm}$ ) tetapi dapat membawa perangkat pemadam yang kecil berbentuk seperti paying terbalik dan perangkat sensor pendukung. UAV yang didesain berbentuk multicopter dengan 6 baling-baling. Bentuk desain multicopter terdapat pada Gambar 1. Dilengkapi model kamera jarak dan RGB untuk memantau daerah sekitar [20-22].

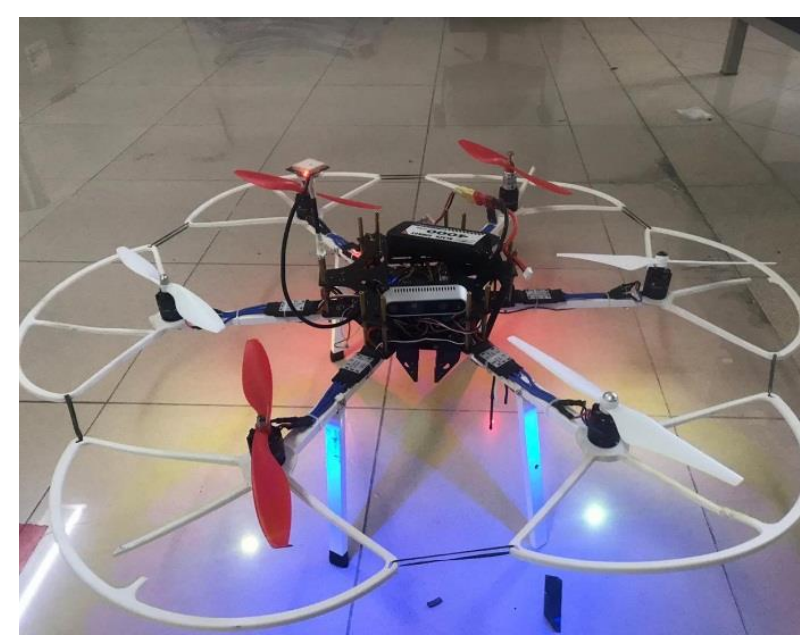

Gambar 1. Desain multicopter berbentuk hexacopter

Robot ini dapat memonitor keadaan sekitar dan memadamkan api. Selanjutnya, robot UAV ini dapat meningkatkan keselamatan, produktivitas, kualitas, dan efisiensi tugas yang diberikan. Kelebihan robot yang dibangun lebih lengkap untuk permasalahan pemadan kebakaran dibandingkan Matrice 200 dan DSLRPros Matrice 210. Matrice 200 dan DSLRPros Matrice 210 tidak 
memiliki perangkat untuk memadamkan api dan harganya juga mahal. Sedangkan robot UAV yang dirancang untuk harga yang lebih murah.

\section{Metodelogi}

Pelaksanaan penelitian ini, dilakukan dengan beberapa tahapan seperti pada Gambar 2.

Pada tahapan awal, sebelum melakukan perancangan sistem robot UAV maka perlu melakukan survey lapangan ke dinas pemadam kebakaran terkait kebutuhan dan permasalahan yang terjadi pada saat melakukan pemadaman terutama hal-hal yang terkait dengan sistem yang dikembangkan.

Dalam membangun penelitian sistem multicopter untuk pemadam kebakaran dijabarkan dalam tiga bagian. Bagian pertama adalah skema mekanis, diikuti oleh deskripsi perangkat keras dan yang terakhir pada desain sistem pada robot AUV.

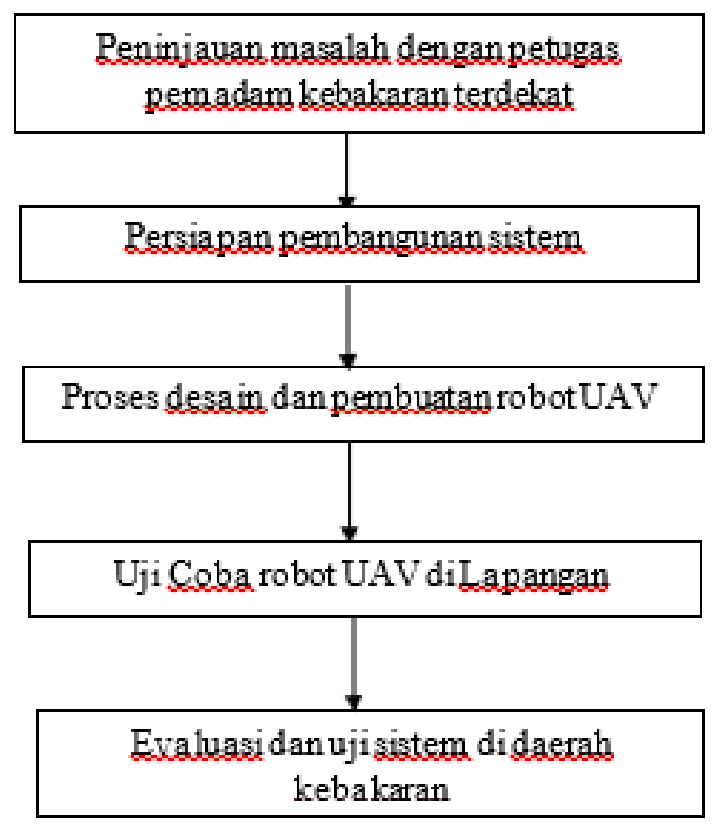

Gambar 2. Metodologi penelitian

\subsection{Desain Multicopter}

Jenis multicopter yang digunakan adalah berbentuk hexacopter dengan pertimbangan kemampuan mengangkat beban yang lebih besar dan kecepatan yang mudah dikendalikan di ruangan yang sempit. Mekanik dasar multicopter dilapisi plat akrilik untuk melindungi sirkuit elektronik. Tubuh sasis akrilik berisi lubang yang memudahkan pemasangan berbagai jenis sensor dan komponen mekanis lainnya.
Pada hexacopter juga terdapat kamera kecil yang digunakan untuk monitor keadaan lingkungan sekitar, dan griper untuk memegang alat pemadam yang dirancang. Struktur hexacopter ditunjukkan pada Gambar 3.

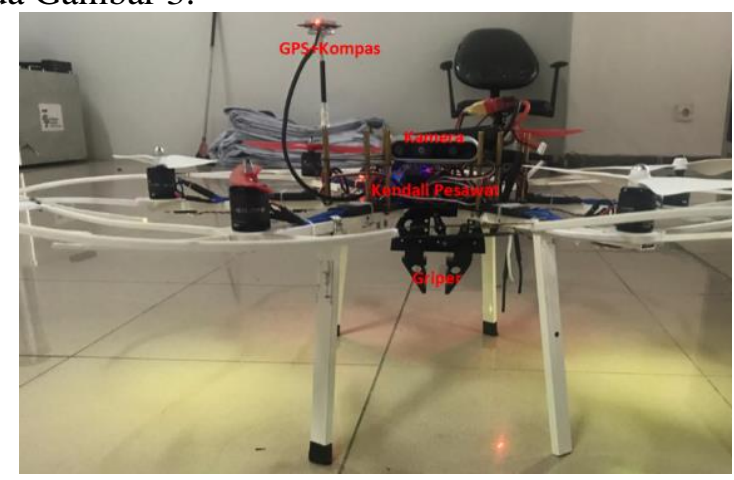

Gambar 3. Struktur perangkat hexacopter yang didesain

\subsection{Desain Alat Pemadam}

Struktur alat pemadam yang dirancang berupa payung yang terbalik. Pada bagian kain penadah hujan diganti dengan kain pemadam yang dapat menahan api. Alat pemadam api dapat dilihat pada Gambar 4.

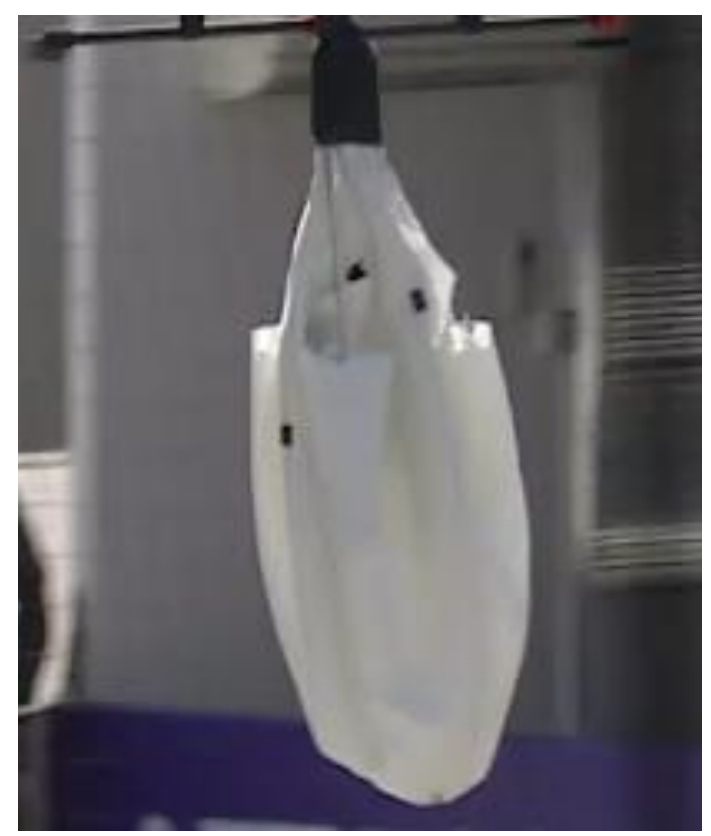

Gambar 4. Alat pemadam yang dirancang

Alat pemadam tersebut akan dibawa oleh multicopter untuk dilemparkan ke daerah kebakaran. Kemudian alat pemadam kebakaran tersebut akan terbuka secara otomatis dan menutup api. Detail cara kerja alat pemadam terdapat pada Gambar 5. 


\subsection{Desain Perangkat Keras}

Perangkat keras adalah salah satu bagian penting dalam pengembangan multicopter.

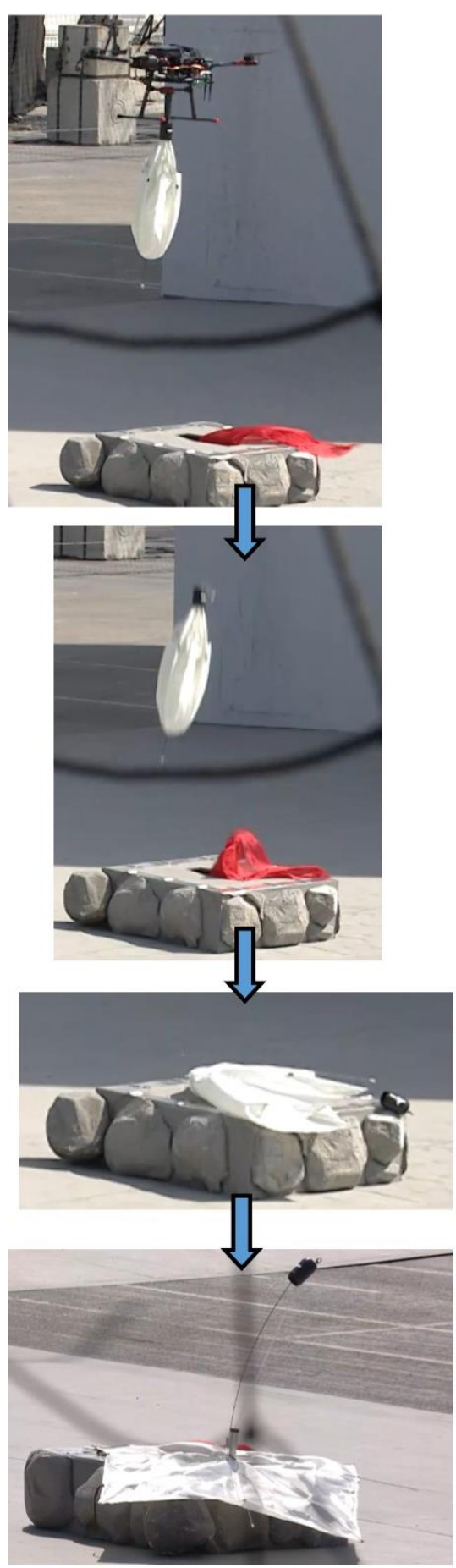

Gambar 5. Cara kerja alat pemadam kebakaran dari diangkut oleh multicopter hingga dilepaskan ke titik api.

Perangkat keras sistem ini terdiri dari beberapa jenis sensor, mikrokontroler sebagai flight controller, motor dengan propeller, telemetri, remote pengendali dan alat pemadam. Gambar 6 menunjukkan diagram blok dari operasi robot UAV yang didesain, terdiri dari sensor api dan kemera kecil sebagai input dari sistem. Mikrokontroler digunakan untuk menghubungkan inputan dari sistem yang ada. Sedangkan perangkat pemadamnya menggunakan pemadam api dengan ukuran yang kecil yang akan bekerja ketika operator memberikan perintah menggunakan remote untuk menggerakkan actuator melepaskan parasut pemadam api. Di sisi lain, operator dapat memonitor pergerakan robot dengan menggunakan kamera kecil yang terhubung ke perangkat monitor pada petugas pemadam.

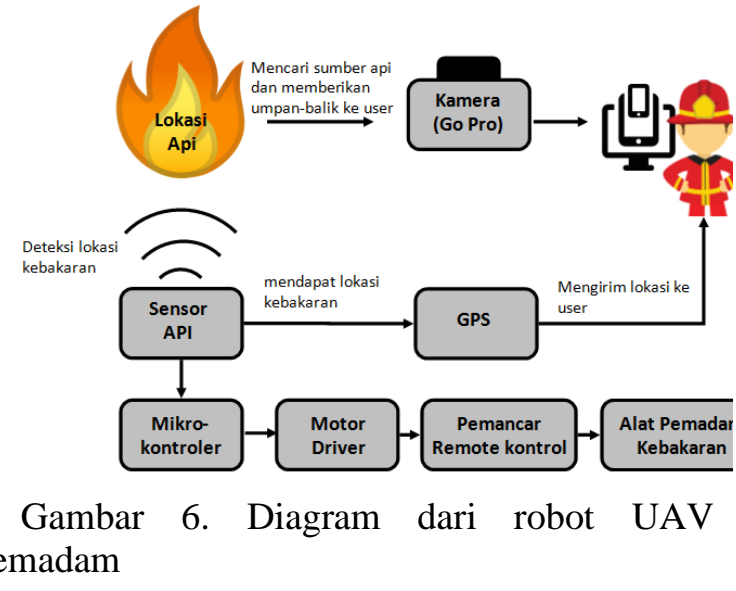

Sensor api merupakan bagian penting dalam membangun robot pemadam kebakaran karena digunakan sebagai mata robot untuk menemukan api. Sensor ini dapat mengidentifikasi api berdasarkan panjang gelombang cahaya pada 760 $\mathrm{nm}$ hingga $1100 \mathrm{~nm}$. Sudut dan jarak deteksinya sekitar $60^{\circ}$ dan jarak $20 \mathrm{~cm}$ hingga $100 \mathrm{~cm}$.

Sensor api pada kebanyakan robot pemadam kebakaran, adalah bagian penting dalam investigasi, yang selalu digunakan sebagai mata robot untuk menemukan sumber api [1]. Sedangkan GPS adalah perangkat untuk mengetahui lokasi robot. Sensor api pada robot UAV berjumlah 8 yang akan dipasang membentuk sudut melingkar. Memiliki fungsi untuk mendeteksi dan memberikan kondisi suhu di sekitar robot, dengan tujuan agar robot dalam keadaan aman. Selain sensor api, sensor kamera juga dipasang pada robot untuk membantu mengamati area terjadinya kebakaran.

Motor yang dilengkapi propeller digunakan sebagai sumber penggerak multicopter untuk dapat terbang. UAV yang dirancang adalah hexacopter sehingga memiliki enam set motor dan propeller. 
Tenaga untuk setiap motornya adalah sekitar 10V hingga $16 \mathrm{~V}$ DC. Sedangkan rasio propellernya adalah berdiameter 10 inch. Dan kecepatan putar motornya adalah $880 \mathrm{rpm}$. Sehingga dapat mengangkat terbang dengan beban tambahan maksimal $2 \mathrm{Kg}$. $2 \mathrm{Kg}$ tersebut tidak termasuk berat multicopter sendiri.

Pemancar dan penerima remote kontrol nirkabel yang digunakan memiliki 4 mode kontrol. Nomor model nya adalah S4C-AC110. Remote ini memiliki empat tombol. Tegangan pengoperasian untuk kendali jarak jauh ini adalah AC $100-120 \mathrm{~V}$, sedangkan kisaran tegangan kerja relai adalah AC $110-240 \mathrm{~V}$ atau DC $0-28 \mathrm{~V}$. Jumlah model pemancar adalah C-4. Jarak kendali jarak jauh adalah $100 \mathrm{~m}$ atau 300 kaki. Catu daya untuk pemancar ini adalah $12 \mathrm{~V}$. Frekuensi pemancaran adalah $315 \mathrm{MHz} / 433 \mathrm{MHz}$. Dengan memanfaatkan pemancar dan kendali jarak jauh, multicopter dapat dikendalikan dari tempat yang jauh di mana operator yang mengendalikannya akan berada di tempat yang aman sementara multicopter akan masuk ke area kebakaran yang berbahaya.

Detail perangkat multicopter yang digunakan adalah pada Tabel 1 .

Tabel 1. Detail Perangkat Multicopter

\begin{tabular}{|c|c|c|c|}
\hline No & Nama & Jumlah & Deskripsi \\
\hline 1 & $\begin{array}{c}\text { Propeller } \\
1045\end{array}$ & 6 & $\begin{array}{l}\text { Baling-baling } \\
\text { multicopter }\end{array}$ \\
\hline 2 & $\begin{array}{l}\text { Propeller } \\
\text { Guard }\end{array}$ & 6 & $\begin{array}{l}\text { Pelindung agar } \\
\text { propeller tidak } \\
\text { mudah pecah }\end{array}$ \\
\hline 3 & $\begin{array}{l}\text { T-Motor } \\
880 \mathrm{Kv}\end{array}$ & 6 & $\begin{array}{c}\text { Aktuator } \\
\text { penggerak }\end{array}$ \\
\hline 4 & $\begin{array}{c}\text { Pixhawk } 3.8 \\
\text { Lipo }\end{array}$ & 1 & Pesawak kendali \\
\hline 5 & $\begin{array}{c}\text { Batrery } \\
11.1 \mathrm{v}\end{array}$ & 1 & Sumber tegangan \\
\hline 6 & ESC 30A & 6 & Pengendali motor \\
\hline 7 & Telemetri & 1 & $\begin{array}{l}\text { Pelapor informasi } \\
\text { jarak jauh }\end{array}$ \\
\hline 8 & $\begin{array}{c}\text { Frame } \\
\text { Multicopter }\end{array}$ & 1 & $\begin{array}{l}\text { Memiliki dimensi } \\
550 \mathrm{~cm} \text { tanpa } \\
\text { propeller }\end{array}$ \\
\hline
\end{tabular}

\section{Hasil dan Pembahasan}

Pada penelitian ini UAV dirancang hanya dapat mengangkat beban seberat $2 \mathrm{~kg}$. Kemudian UAV digunakan untuk menggunakan payung mekanikal yang dirancang untuk memadamkan api. Setelah itu sebagai pembanding percobaan juga dilakukan menggunakan air untuk pembuktuian bahwa rancangan payung tersebut adalah alat yang efesien untuk memadamkan api. Air yang diangkut hanya sebanyak 2 liter. Hal ini dikarenakan daya angkut maksimal UAV. Berbanding sama dengan payung pemadam memiliki berat $1,6 \mathrm{~kg}$ sehingga hanya dapat mengangkat 1 payung pemadam. Sehingga perbandingannya diambil dari berat material pemadamnya. Dengan 2 liter air memiliki berat air kurang lebih $2 \mathrm{Kg}$ dibandingkan berat payung pemadamnya $1.6 \mathrm{~kg}$.

Pada bagian ini jugs akan membuktikan perbandingan perhitungan dengan menggunakan ecalc dan realita percobaan. eCalc adalah aplikasi untuk menghitung keberhasilan terbangnya multicopter berdasarkan ilmu fisika dan model matematika yang mampu mensimulasikan karakteristik penerbangan multicopter hanya dengan memilih pengaturan perangkat yang kita desain. Berikut desain perangkat yang digunakan terdapat pada Gambar 7.

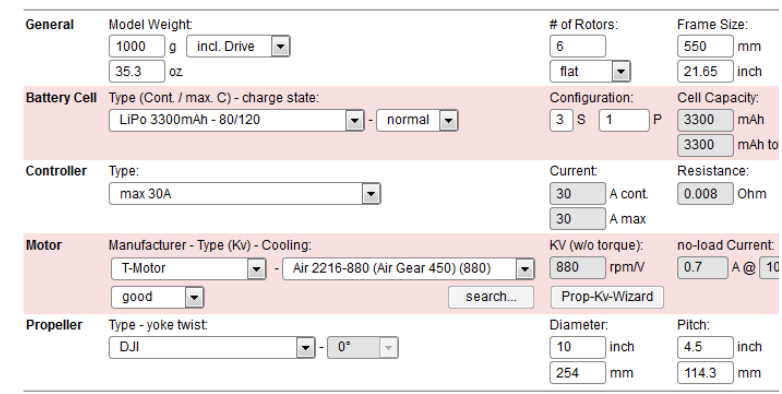

\section{Gambar 7. Perangkat yang digunakan menggunakan eCal untuk simulasi}

Dari perhitungan eCalc menghasilkan beberapa informasi yang dijelaskan pada Tabel 2. Dari informasi tersebut memiliki kesimpulan bahwa multicopter dapat terbang dengan setabil.

Tabel 2. Detail hasil perhitungan eCalc

\begin{tabular}{|c|c|c|}
\hline No & Nama & Hasil \\
\hline 1 & $\begin{array}{c}\text { Daya angkut } \\
\text { maksimal }\end{array}$ & $2088 \mathrm{~g}$ \\
2 & $\begin{array}{c}\text { Kecepatan } \\
\text { maksimal } \\
\text { Daya panjat } \\
\text { ke atas } \\
\text { Lama } \\
\text { terbang }\end{array}$ & $59 \mathrm{~km} / \mathrm{h}$ \\
4 & 18.9 menit \\
\hline
\end{tabular}

Kemudian dari percobaan realitanya adalah menghasilkan pada Table 3.

Tabel 3. Detail hasil percobaan realita

\begin{tabular}{|c|c|c|}
\hline No & Nama & Hasil \\
\hline 1 & $\begin{array}{c}\text { Daya angkut } \\
\text { maksimal } \\
\text { Kecepatan } \\
\text { maksimal }\end{array}$ & $47 \mathrm{~km} / \mathrm{h}$ \\
3 & $\begin{array}{c}\text { Daya panjat ke } \\
\text { atas } \\
4\end{array}$ & $7.3 \mathrm{~m} / \mathrm{s}$ \\
Lama terbang & 15 menit \\
\hline
\end{tabular}


Pada percobaan realita dilakukan dengan beberapa cara. Pada bagian pertama adalah mengukur daya angkut multicopter diberi beban setiap kelipatan 100 gram hingga multicopter tidak dapat naik ke udara. Pada bagian kedua adalah kecepatan maksimal dengan keadaan multicopter tanpa beban tambahan dijalankan mengelilingi jalur yang telah ditentukan dan dihitung kecepatannya. Ketiga daya panjat ke atas adalah kecepatan multicopter terbang ke atas tanpa beban tambahan. Pada bagian terakhir adalah lama terbang. Pada bagian ini multicopter diterbangkan hingga tegangan batrai turun menjadi 10 volt.

Tabel 4. Detail percobaan pemadaman menggunakan air maksimal air 2 liter

\begin{tabular}{|c|c|c|c|}
\hline Percobaan & Air (liter) & Waktu $(\mathrm{s})$ & Keterangan \\
\hline 1 & 1 & 34 & Padam \\
2 & 1.1 & 51 & Padam \\
3 & 1.6 & 54 & Padam \\
4 & 1 & 47 & Padam \\
5 & 1.4 & 39 & Padam \\
6 & 1.2 & 56 & Padam \\
7 & 1.1 & 10 & Padam \\
8 & 0.9 & 12 & Padam \\
9 & 1.8 & 47 & Padam \\
10 & 1.4 & 42 & Padam \\
11 & 1.6 & 10 & Padam \\
12 & 1.3 & 13 & Padam \\
13 & 1.1 & 31 & Padam \\
14 & 0.8 & 38 & Padam \\
15 & 1.1 & 40 & Padam \\
16 & 1.2 & 19 & Padam \\
17 & 1.7 & 14 & Padam \\
18 & 1.9 & 46 & Padam \\
19 & 0.8 & 12 & Padam \\
20 & 1.9 & 57 & Padam \\
\hline
\end{tabular}

Selanjutnya adalah percobaan untuk membuktikan bahwa rancangan alat pemadam adalah efisien dibandingkan menggunakan air. Pada percobaan pemadam pertama menggunakan air untuk memadamkan api kecil di tanah. Berapa banyak air yang dikeluarkan untuk memadamkan api dan berapa lama api dapat padam. Berikut hasil percobaan dapat terlihat pada Tabel 4. Rata rata waktu yang digunakan untuk memadamkan api adalah 37.5 detik. Sedangkan air yang dibutuhkan adalah 1.4 liter.
Tabel 5. Percobaan pemadaman menggunakan rancangan alat pemadam berupa payung pemadam

\begin{tabular}{|c|c|c|}
\hline Percobaan & Waktu (s) & Keterangan \\
\hline 1 & 6 & Padam \\
2 & 8 & Padam \\
3 & 9 & Padam \\
4 & 9 & Padam \\
5 & 4 & Padam \\
6 & 4 & Padam \\
7 & 5 & Padam \\
8 & 4 & Padam \\
9 & 3 & Padam \\
10 & 5 & Padam \\
11 & 4 & Padam \\
12 & 8 & Padam \\
13 & 8 & Padam \\
14 & 4 & Padam \\
15 & 7 & Padam \\
16 & 5 & Padam \\
17 & 10 & Padam \\
18 & 5 & Padam \\
19 & 7 & Padam \\
20 & 5 & Padam \\
\hline
\end{tabular}

Selanjutnya adalah percobaan menggunakan rancangan alat pemadam berupa payung pemadam api. Detail percobaan terdapat pada Tabel 5. Pada Tabel 5 terlihat api dapat lebih cepat padam dengan rata-rata waktu 5 detik.

\section{Kesimpulan}

Desain UAV yang berbentuk multicopter telah berhasil terbang dengan beban tambahan lebih dari 2000 g. Percobaan telah berhasil membuktikan bahwa perhitungan menggunakan eCalc dan kenyataan tidak berbeda jauh. Pada perhitungan eCalc menghasilkan analisa bahwa multicopter yang dirancang dapat terbang dengan beban tambahan, kecepatan maksimal, daya panjat ke atas, dan lama terbang tidak berbeda jauh dari percobaan kenyataan yang dilakukan. Rancangan alat pemadam untuk UAV telah berhasil 100\% memadamkan api. Waktu yang dibutuhkan untuk memadamkan api juga lebih cepat yaitu dengan rata-rata api padam selama 5 detik dibandingkan menggunakan air membuat api padam rata-rata waktu 37.5 detik. Hal ini terjadi dikarenakan pemadaman menggunakan air lebih sulit untuk menargetkan ke titik api. Hal ini terjadi karena keadaan angin dilingkungan luar cukup kencang 
sehingga semburan air tidak dapat langsung ke target api sedangkan dengan pemadam yah telah di rancang dapat lebih cepat karena dapat langsung jatuh ke titik api kemudian membuka bagian kepala payung untuk menutup seluruh api sehingga api dapat lebih cepat padam.

\section{Daftar Pustaka}

[1] Pratomo, Setyawan Wahyu, "Perancangan Sistem Transfer Daya Nirkabel untuk Unmanned Aerial vehicle (UAV) Micro Jenis Quadcopter," Jurnal Nasional Teknik Elektro 5.3 (2016): 396-404.

[2] Aliff, Mohd, Shujiro Dohta, and Tetsuya Akagi, "Simple Trajectory Control Method of Robot Arm Using Flexible Pneumatic Cylinders," Journal of Robotics and Mechatronics 27, no. 6: 698-705, 2015.

[3] Aliff, Mohd, Shujiro Dohta, and Tetsuya Akagi, "Control and analysis of simplestructured robot arm using flexible pneumatic cylinders," International Journal of Advanced and Applied Sciences 4, no. 12: 151-157, 2017.

[4] Aliff, Mohd, Shujiro Dohta, and Tetsuya Akagi, "Control and analysis of robot arm using flexible pneumatic cylinder," Mechanical Engineering Journal 1, no. 5: DR0051-DR0051, 2014.

[5] Aliff, Mohd, Shujiro Dohta, and Tetsuya Akagi, "Trajectory controls and its analysis for robot arm using flexible pneumatic cylinders," In 2015 IEEE International Symposium on Robotics and Intelligent Sensors (IRIS), pp. 48-54. IEEE, 2015.

[6] Aliff, Mohd, Shujiro Dohta, and Tetsuya Akagi, "Trajectory control of robot arm using flexible pneumatic cylinders and embedded controller," In 2015 IEEE International Conference on Advanced Intelligent Mechatronics (AIM), pp. 1120-1125. IEEE, 2015.

[7] Xin, Cao, Dou Qiao, Shi Hongjie, Li Chunhe, and Zhang Haikuan. "Design and implementation of debris search and rescue robot system based on internet of things." In 2018 International Conference on Smart Grid and Electrical Automation (ICSGEA), pp. 303-307. IEEE, 2018.

[8] YUSOF, MI, and TONY DODD. "Pangolin: A variable geometry tracked vehicle with independent track control." In Field Robotics, pp. 917-924. 2012.
[9] Day, Chia-Peng. "Robotics in industry - their role in intelligent manufacturing." Engineering 4, no. 4 : 440-445, 2018.

[10] Lee, Jin-Won, Gi-Tae Park, Jae-Sub Shin, and Jong-Woon Woo. "Industrial robot calibration method using denavit-Hatenberg parameters." In 2017 17th International Conference on Control, Automation and Systems (ICCAS), pp. 1834-1837. IEEE, 2017.

[11] Tanaka, Fumihide, Toshimitsu Takahashi, Shizuko Matsuzoe, Nao Tazawa, and Masahiko Morita. "Telepresence robot helps children in communicating with teachers who speak a different language." In Proceedings of the 2014 ACM/IEEE international conference on Human-robot interaction, pp. 399-406. 2014.

[12] Ahn, Jong-gil, and Gerard J. Kim. "Remote collaboration using a tele-presence mobile projector robot tele-operated by a smartphone." In 2016 IEEE/SICE International Symposium on System Integration (SII), pp. 236-241. IEEE, 2016.

[13] Harik, El Houssein Chouaib, and Audun Korsaeth. "Combining hector slam and artificial potential field for autonomous navigation inside a greenhouse." Robotics 7 , no. 2 (2018): 22.

[14] Calderon, Carlos Antonio Acosta, Elara Rajesh Mohan, and Buck Sin Ng. "Development of a hospital mobile platform for logistics tasks." Digital Communications and Networks 1, no. 2 (2015): 102-111.

[15] Setyawan, Dwi Edi. "Sistem Robot Penyelamat Menggunakan Metode Deteksi Viola-Jones untuk Membantu Tim Penyelamat Menemukan Korban Bencana." ELKHA: Jurnal Teknik Elektro 11, no. 1: 2732, October 2019.

[16] Hyung, Hyun-Jun, Byeong-Kyu Ahn, Brian Cruz, and Dong-Wook Lee. "Analysis of android robot lip-sync factors affecting communication." In 2016 11th ACM/IEEE International Conference on Human-Robot Interaction (HRI), pp. 441-442. IEEE, 2016.

[17] Haksar, Ravi N., and Mac Schwager. "Distributed deep reinforcement learning for fighting forest fires with a network of aerial robots." In 2018 IEEE/RSJ International Conference on Intelligent Robots and Systems (IROS), pp. 1067-1074. IEEE, 2018. 
[18] Raju, Joyal, S. Sheik Mohammed, Johaan Varkey Paul, Georgy Abel John, and Dinanath S. Nair. "Development and implementation of arduino microcontroller based dual mode fire extinguishing robot." In 2017 IEEE International Conference on Intelligent Techniques in Control, Optimization and Signal Processing (INCOS), pp. 1-4. IEEE, 2017.

[19] Bogue, Robert. "Robotic exoskeletons: a review of recent progress." Industrial Robot: An International Journal (2015).

[20] Al Farouq, Ardiansyah, Raden Sanggar Dewanto, and Dadet Pramadihanto. "Transformed Stereo Vision and Structure Sensor for Development 3D Mapping on" FLoW" Humanoid Robot in Real Time." Journal of Telecommunication, Electronic and Computer Engineering (JTEC) 9, no. 2-5 (2017): 129-133.

[21] Anjarlistiawan, Rimsya, Ardiansyah Al Farouq, Sritrusta Sukaridhoto, Raden Sanggar Dewanto, and Dadet Pramadihanto. "Multi process matching depth image between stereo camera and structure sensor in realtime." In 2017 International Electronics Symposium on Engineering Technology and Applications (IES-ETA), pp. 134-139. IEEE, 2017.

[22] Al Farouq, Ardiansyah, Presto Fani, and Muhammad Yanuar Muhaimin. "Analisa Kesalahan Trajektori dan Algoritma Solusi Invers pada Robot Lengan Berdasarkan Jaringan QACA-RBF." Journal of Computer, Electronic, and Telecommunication 1, no. 1, 2020. 